\title{
ANÁLISE DA TERCEIRIZAÇÃO DA MANUTENÇÃO SOB A ÓTICA DOS CUSTOS E IMPACTOS ECONÔMICOS: REVISÃO BIBLIOGRÁFICA
}

\author{
ANALYSIS OF MAINTENANCE OUTSOURCING FROM THE VIEW OF COSTS AND ECONOMIC \\ IMPACTS: LITERATURE REVIEW
}

\author{
$\underline{\text { Ana Luíza Ferreira Mamede }}^{\mathbf{1}}, \boldsymbol{\&}$ André Alves de Resende ${ }^{{ }^{*}}$ \\ ${ }^{12}$ Universidade Federal de Catalão - UFCAT, Catalão, Brasil. \\ 1 analuizafmamede@gmail.com 2* aaresende@gmail.com
}

\section{ARTIGO INFO.}

\section{Recebido em: 19.04.2021}

Aprovado em: 27.05.2021

Disponibilizado em: 23.06.2021

Palavras-chave:

Terceirização; manutenção; custos .

\section{KEYWORDS:}

Outsourcing; maintenance; costs.

*Autor Correspondente: Resende, A. A. de

\section{RESUMO}

$\mathrm{O}$ conceito de terceirização de processos traz consigo, automaticamente, a ideia de ganho econômico para a empresa contratante. Porém, a terceirização envolve diversos aspectos importantes, como a legalidade, qualidade, segurança, disponibilidade, entre outros. Dessa forma, torna-se necessário avaliar detalhadamente as vantagens e desvantagens que serão obtidas com o processo de terceirização, de acordo com o setor e a atividade que será terceirizada, para então entender como ela impactará economicamente a empresa. A atividade de manutenção, normalmente, é uma atividade-meio, e por isso é muito comum que seja terceirizada. Diante disso, o presente trabalho consiste em uma revisão da literatura partindo de pesquisas bibliográficas a fim de analisar a terceirização da manutenção com foco nos custos e impactos econômicos. Os resultados encontrados comprovaram que nem sempre o processo de terceirização será vantajoso economicamente para as organizações.

\begin{abstract}
The concept of process outsourcing brings with it, automatically, the idea of economic gain for the contracting company. However, outsourcing involves several important aspects, such as legality, quality, security, availability, among others. In this way, it becomes necessary to evaluate in detail the advantages and disadvantages that will be obtained with the outsourcing process, according to the sector and the activity that will be outsourced, so as to understand how it will impact the company economically. Maintenance activity is usually a middle activity, so it is very common for it to be outsourced. Faced with this, the present work consists of a literature review based on bibliographic research in order to analyze the outsourcing of maintenance with a focus on costs and economic impacts. The results found proved that the outsourcing process will not always be economically advantageous for organizations.
\end{abstract}




\title{
INTRODUÇÃO
}

O fenômeno da globalização estabelece um cenário competitivo que faz com que as empresas busquem constantemente estratégias de crescimento. Neste contexto encontra-se o dilema entre fazer uma atividade internamente ou terceirizar. A partir da crença de que centrando esforços nas atividades-fim é possível garantir maior competitividade, as empresas estão utilizando a estratégia de terceirização de diversos processos em sua cadeia de valor (Azevedo, 2015).

A terceirização está presente no cotidiano empresarial, tendo se consolidado no Brasil nos últimos 30 anos como um recurso estratégico que, se utilizado adequadamente, pode proporcionar diversos resultados positivos. O conceito de terceirização está associado a necessidade de uma relação de parceria (Kardec \& Nascif, 2019):

\begin{abstract}
"Terceirizar passa pelo pressuposto básico de uma relação de parceria, por uma atuação semelhante com a contratante e, sobretudo, que seja uma relação de resultados empresariais para as partes envolvidas, trazendo vantagem competitiva para a empresa contratante e para a empresa contratada através de uma maior especialização, comprometimento com resultados e autonomia gerencial, que se traduzirão em maiores ganhos.” (Kardec \& Nascif, 2019, p. 283)
\end{abstract}

As atividades de uma empresa podem ser divididas em três modalidades, sendo: as atividadesfim, que se tratam da razão de ser do negócio; as atividades-meio, que estão ligadas à atividade fim, como a manutenção; e as atividades acessórias, aquelas que são necessárias, mas não são intimamente ligadas às atividades-fim, como a limpeza e segurança. Os serviços terceirizados, normalmente, se restringem às atividades-meio e acessórias (Kardec \& Nascif, 2019).

A terceirização da atividade de manutenção não é encontrada apenas em indústrias, sendo aplicada também a outros setores da economia como prática estratégica para redução de custos. É o caso do setor de saúde, especialmente hospitais públicos, por terem menos funcionários qualificados ou recursos para a realização da manutenção internamente (Cruz \& Rincon, 2012).

De acordo com os dados do Documento Nacional apresentados em 2013 pela Associação Brasileira de Manutenção e Gestão de Ativos (ABRAMAN), as indústrias brasileiras investem em manutenção o correspondente a 4,69\% do PIB nacional, sendo que esta tendência é crescente. $\mathrm{O}$ documento apontou também que, em média, os serviços contratados representam 25,13\% da composição dos custos de manutenção. Além do mais, também indicou que "qualidade e preço" são os fatores mais relevantes para as empresas no momento da contratação de serviços.

Murthy, Karim e Ahmadi (2015) apontaram diversos motivos que fazem as empresas optarem pela terceirização, como a redução de custos gerais, redução de riscos e melhoria de processos. Todavia, também destacaram algumas questões que devem ser analisadas antes da decisão, como avaliar se a organização está preparada para isso, quais as atividades podem ser terceirizadas, quais os riscos potenciais, formas de contratação, entre outros. Logo, as empresas precisam avaliar em quais situações é mais viável realizar a terceirização da manutenção. Além disso, os autores afirmaram que a literatura sobre o tema é bastante 

econômicos: revisão bibliográfica. Brazilian Journal of Production Engineering, 7(2), 155-168.

limitada, sendo que os estudos relevantes exploram questões muito específicas, como os modelos de contratos. Tarakci, Tang e Teyarachakul (2009) também evidenciaram a escassez de estudos relativos à terceirização da manutenção, sendo que, até o momento do estudo, encontraram apenas cinco artigos de pesquisa abordando o tema.

Diante disso, o presente estudo justifica-se pela importância das informações para uma tomada de decisão mais adequada em relação a terceirizar ou não uma atividade de manutenção. Portanto, tem o objetivo de realizar uma revisão da literatura a fim de responder a seguinte pergunta norteadora: "Em relação aos custos, a terceirização é a opção mais viável?". Para isso, o estudo inicia-se com um levantamento bibliográfico seguido de uma revisão sistemática da literatura a fim de identificar documentos relevantes sobre o tema. Através dos resultados, pretende-se verificar lacunas que ainda persistem sobre o tema.

\title{
REFERENCIAL TEÓRICO
}

Acredita-se que as primeiras noções a respeito dos serviços terceirizados no Brasil ocorreram na década de 1950, momento em que as empresas privadas começaram o processo de contratação de serviços e produtos de outras empresas. Tal processo foi evidenciado na década de 1960 por meio das empresas multinacionais que estavam se estabelecendo no país. Já na década de 1970, foi promulgada a Lei nº 6.019 de janeiro de 1974 que versou sobre o trabalho temporário, não havendo, portanto, uma legislação específica a respeito do assunto (Frez \& Mello, 2017).

A Lei $n^{\circ}$ 6.019/1974, que dispôs sobre as relações de trabalho na empresa de prestação de serviços a terceiros, passou por algumas alterações por meio da Lei ${ }^{\circ} 13.429$ de 31 de março de 2017, conhecida também como Lei da Terceirização. Com isso, define a empresa prestadora e suas obrigações:

\begin{abstract}
Art. $4^{\circ}$-A. Considera-se prestação de serviços a terceiros a transferência feita pela contratante da execução de quaisquer de suas atividades, inclusive sua atividade principal, à pessoa jurídica de direito privado prestadora de serviços que possua capacidade econômica compatível com a sua execução. $\S 1^{\circ}$ A empresa prestadora de serviços contrata, remunera e dirige o trabalho realizado por seus trabalhadores, ou subcontrata outras empresas para realização desses serviços. $§ 2^{\circ}$ Não se configura vínculo empregatício entre os trabalhadores, ou sócios das empresas prestadoras de serviços, qualquer que seja o seu ramo, e a empresa contratante." (Brasil, 1974).
\end{abstract}

Além disso, a Lei no 13.429/2017 apresentou artigo permitindo que quaisquer atividades, incluindo as atividades-fim, sejam delegadas a empresas terceiras. Antes, havia o entendimento que somente as atividades-meio e acessórias poderiam ser terceirizadas.

A atividade de manutenção era vista como um mal necessário e representava uma fonte de custos e gastos considerados desnecessários. Com o novo cenário de economia globalizada e extremamente competitiva, a busca por excelência operacional se tornou constante e as mudanças acontecem rapidamente, dessa forma a manutenção passou a ser considerada uma atividade fundamental. Devido a sofisticação dos equipamentos, máquinas e instalações, a manutenção precisa ser, por vezes, mais eficiente que as próprias instalações, exigindo profissionais e métodos qualificados, assim, configura um desafio para as gerências de manutenção (Leal et al., 2015). 

econômicos: revisão bibliográfica. Brazilian Journal of Production Engineering, 7(2), 155-168.

Tavares, Gonzaga e Poydo (2005) afirmaram que a manutenção, devido à influência direta na capacidade produtiva e no custo operacional dos equipamentos, se correlaciona com a rentabilidade da empresa. Ao passo que as atividades de manutenção aumentam a disponibilidade e desempenho dos equipamentos, colabora para o acréscimo nos custos de fabricação. Logo, o objetivo deve ser alcançar o equilíbrio para maximizar a contribuição da manutenção na rentabilidade da instituição. Os autores destacam que para ser uma fonte geradora de receita a manutenção precisa focar em três pontos, sendo: desenvolvimento, buscar projetos que permitam baixar os custos, executando as intervenções com menor tempo e/ou menores gastos; disponibilidade, investir em ações que aumentam a receita com baixo ou nenhum investimento de capital; e economia, que pode ser obtida eliminando ou reduzindo investimentos em métodos ou itens que não são estratégicos e, também, por meio da adoção de serviços terceirizados.

Kardec e Nascif (2013) apontaram que a manutenção é fundamental para o processo produtivo, possuindo uma função estratégica na organização. Logo, a forma como a sua gestão é conduzida acarreta melhores ou piores resultados. Ao terceirizar o processo de manutenção a empresa contratante tem como foco a melhoria dos resultados mediante o aumento da confiabilidade e disponibilidade dos ativos. Dessa forma, a empresa terceirizada deve ter o mesmo foco a fim de atender as expectativas e obter os resultados para a contratante.

A Sondagem Especial - Terceirização desenvolvida pela Confederação Nacional da Indústria (CNI), de 2017, indicou que 63,1\% das empresas industriais (construção, transformação, extrativa) empregavam serviços terceirizados. O serviço de montagem e/ou manutenção de equipamentos, que anteriormente ocupava o primeiro lugar, passou a ocupar a segunda posição no ranking de atividades terceirizadas mais contratadas pela indústria, com $51,1 \%$. Em primeiro lugar está segurança e/ou vigilância $(51,8 \%)$ e em terceiro logística e transportes $(48,6 \%)$ (Figura 1).

Figura 1. Participação (\%) dos serviços mais terceirizados na indústria.

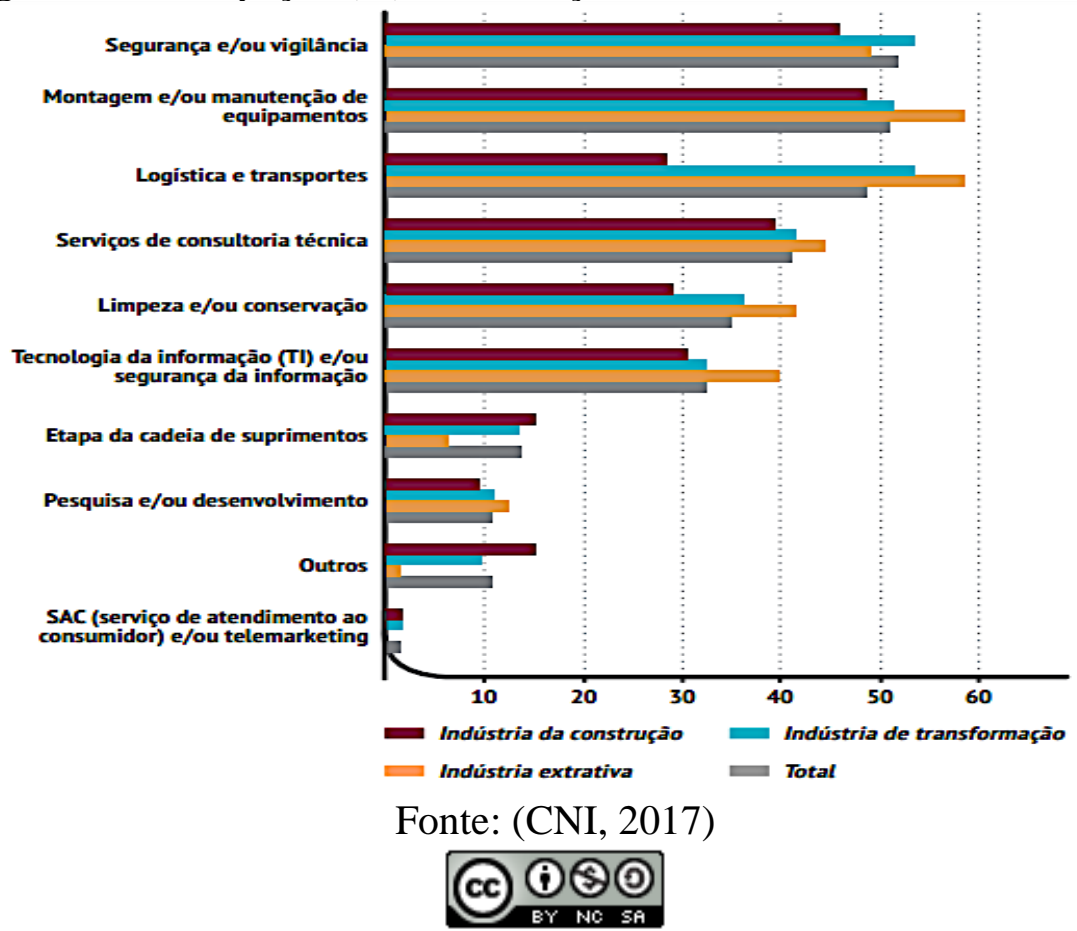



econômicos: revisão bibliográfica. Brazilian Journal of Production Engineering, 7(2), 155-168.

O Documento da CNI destaca ainda que o principal motivo para a terceirização $(88,9 \%)$ é a redução de custos de produção. Tal redução é obtida pela otimização do processo produtivo, implicando em ganhos de eficiência, de escala e melhor aproveitamento de insumos. Outros fatores considerados importantes para a decisão foram, respectivamente, ganho de tempo $(85,9 \%)$, aumento da qualidade do serviço $(83,4 \%)$ e uso de novas tecnologias $(71 \%)$ (CNI, 2017).

Xenos (2014) destacou que o lucro de uma organização depende, entre outros fatores, de um bom gerenciamento dos custos, sendo que os custos derivados da manutenção de equipamentos correspondem a uma parcela dos custos totais. Dessa forma, se a atividade de manutenção for cara em comparação à sua eficácia em prevenir falhas, poderá comprometer as metas de lucro da instituição. A respeito dos custos de manutenção, o autor fez a seguinte afirmação:

\begin{abstract}
"É importante distinguir claramente os custos de manutenção dos investimentos com a compra de equipamentos novos ou com a expansão de instalações existentes. Os custos de manutenção dos equipamentos representam uma parcela dos custos de produção da organização. Para manter os equipamentos, é preciso utilizar peças de reposição, materiais de consumo, energia, mão de obra de gerenciamento e execução, serviços subcontratados, entre outros recursos. Esses custos são geralmente divididos em três categorias distintas: 1) custos de materiais; 2) custos de mão de obra; 3) custos de serviços subcontratados. Além disso, é possível dividir os custos de manutenção de acordo com os métodos de manutenção utilizados, basicamente em custo da manutenção preventiva, custo da manutenção corretiva e custo da melhoria dos equipamentos." (XENOS, 2014, p. 223)
\end{abstract}

Filho (2010) mencionou que as ações de manutenção devem estar financeiramente respaldadas antes de serem iniciadas, devendo ser considerados diversos tipos de custos decorrentes da manutenção além do custo de reparo, como o custo de perda de produção e/ou matéria prima, de acidentes e possíveis indenizações, de retrabalho, de danos ambientais, custos por treinamentos e atualizações de pessoas e equipamentos, bem como a perda por indisponibilidade do equipamento. Logo, os custos devem ser um dos principais motivos de preocupação das organizações, buscando sempre assegurar a disponibilidade dos equipamentos e, consequentemente, a redução dos custos.

\title{
Metodologia
}

Revisões sistemáticas da literatura comumente classificadas como estudos secundários, uma vez que utilizam estudos primários como fonte de dados. Assim, compreende-se que estudos primários são os artigos científicos que apresentam pela primeira vez os resultados de pesquisa. Dessa forma, o preparo das revisões sistemáticas precisa ser realizado de forma abrangente e não tendenciosa, divulgando inclusive o detalhamento dos critérios utilizados para permitir a replicabilidade do procedimento (Galvão \& Pereira, 2014).

De acordo com Malhotra (2001), o estudo desenvolvido pode ser classificado como uma pesquisa qualitativa, uma vez que tem por objetivo realizar uma compreensão contextual qualitativa acerca do assunto, com dados não estatísticos e coleta não-estruturada. $\mathrm{O}$ método aplicado foi o de pesquisa bibliográfica, que consiste em uma busca dos estudos existentes sobre o assunto, através de um planejamento com critérios pré-estabelecidos, como delimitação do tema e subtemas. 

econômicos: revisão bibliográfica. Brazilian Journal of Production Engineering, 7(2), 155-168.

A busca foi realizada em 21 de janeiro de 2021, utilizando as bases de dados eletrônicas Portal de Periódicos da Capes/MEC e Periódicos ScieELO utilizando os termos em inglês "maintenance outsourcing" AND "costs", a fim de localizar estudos relativos aos dois temas (intersecção). Na base da Biblioteca Digital Brasileira de Teses e Dissertações (BDTD) utilizou-se também os termos em português "custos terceirização da manutenção". Além disso, foi definido como delimitação temporal o período de vinte anos, ou seja, 2000 a 2020.

Para fins de seleção dos trabalhos, foram considerados os seguintes critérios de inclusão: I tratar sobre os custos da terceirização da manutenção; II - apresentar modelos de tomada de decisão e viabilidade da terceirização da manutenção. Já os critérios de exclusão utilizados foram: I - foco em custos de terceirização de outras atividades; II - estudos sobre as relações trabalhistas de empresas prestadoras de serviço; III - Foco em modelos de contratação.

\section{RESULTADOS}

Com as buscas por palavras-chaves foram obtidos 343 artigos, sendo 298 no Portal de Periódicos da Capes/MEC, 23 no Periódicos SciELO e 22 teses/dissertações na BDTD. Após a primeira seleção através da leitura de títulos e resumos, 300 trabalhos foram considerados fora do escopo, sendo todos removidos. Dos 21 trabalhos que restaram para leitura na íntegra, um total de 05 artigos e 01 dissertação estavam adequados aos critérios de elegibilidade e foram incluídos na síntese qualitativa. Além disso, um trabalho que foi encontrado fora das bases de dados citadas foi incluído no estudo por se adequar a todos os critérios de elegibilidade, totalizando assim 07 trabalhos para estudo. Não houve busca adicional de trabalhos por meio da lista de referências dos artigos selecionados. O fluxograma completo do procedimento de seleção foi realizado baseado no modelo PRISMA e está apresentado na Figura 2 (Galvão et al., 2015).

O número total de artigos encontrados na busca pode ser considerado baixo, consequentemente, ao fazer a seleção de acordo com os critérios de elegibilidade, o número de trabalhos elegíveis também foi baixo. Mesmo com um recorte temporal alto (20 anos), os resultados indicam uma baixa produção científica sobre o tema.

Entre os trabalhos selecionados para o estudo 02 foram realizados no Brasil e publicados em língua portuguesa, os outros 05 artigos foram publicados em inglês e desenvolvidos em países distintos. As áreas analisadas em cada estudo também foram completamente diferentes umas das outras. Os resultados detalhados estão descritos na Tabela 1, incluindo as revistas ou meio em que foram publicados os trabalhos. 
Citação (APA): Mamede, A. L. F., \& Resende, A. A. de. (2021). Análise da terceirização da manutenção sob a ótica dos custos e impactos econômicos: revisão bibliográfica. Brazilian Journal of Production Engineering, 7(2), 155-168.

Figura 2. Fluxograma do processo de seleção dos artigos incluídos na revisão sistemática baseado no modelo PRISMA.
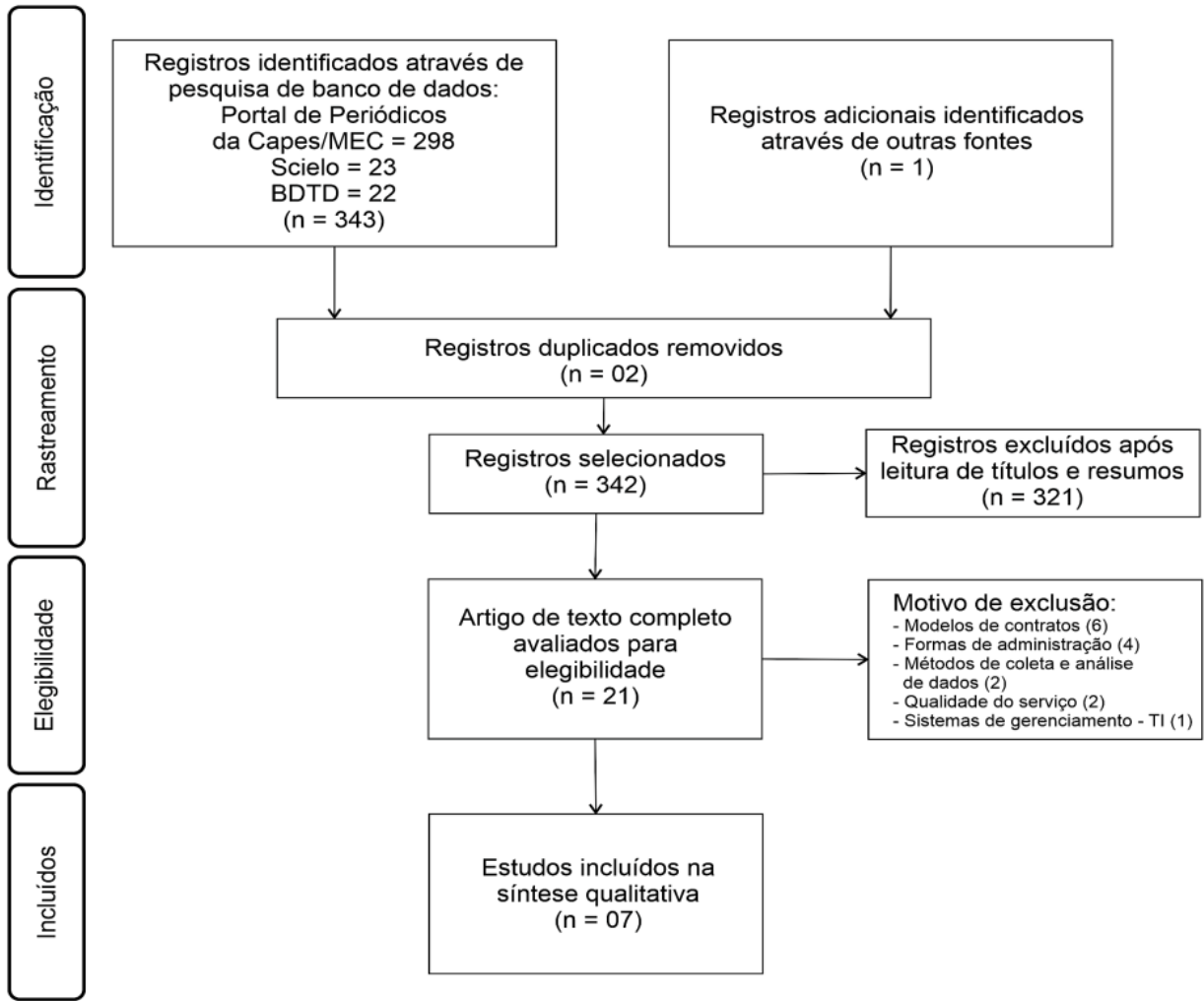

Tabela 1. Opções consideradas mais viáveis (proposta) x adotadas Características da publicacão

\begin{tabular}{|c|c|c|c|c|}
\hline Autores - Ano & Título & Revista & Local do Estudo & Área analisada \\
\hline $\begin{array}{l}\text { Domberger, Jensen } \\
\text { e Stonecash (2002) }\end{array}$ & $\begin{array}{l}\text { Examining The Magnitude } \\
\text { and Sources Of Cost Savings } \\
\text { Associated With Outsourcing }\end{array}$ & $\begin{array}{c}\text { Public Performance \& } \\
\text { Management Review }\end{array}$ & Nova Zelândia & $\begin{array}{l}\text { Veículos em } \\
\text { uma base do } \\
\text { Exército }\end{array}$ \\
\hline Lindemann (2006) & $\begin{array}{l}\text { Modelo de Apoio à Decisão } \\
\text { Estratégica de Terceirização } \\
\text { da Atividade de Manutenção } \\
\text { de Embarcações: Um Estudo } \\
\text { de Caso. }\end{array}$ & $\begin{array}{c}\text { Dissertação (Mestrado) } \\
\text { - PUC do Rio Grande } \\
\text { do Sul }\end{array}$ & $\begin{array}{l}\text { Rio Grande do Sul } \\
\text { (Interior ) }\end{array}$ & Embarcações \\
\hline $\begin{array}{l}\text { Anastasopoulos et } \\
\text { al. }(2010)\end{array}$ & $\begin{array}{l}\text { Cost Savings Analysis of } \\
\text { Performance-Based Contracts } \\
\text { for Highway Maintenance } \\
\text { Operations }\end{array}$ & $\begin{array}{c}\text { Journal Of } \\
\text { Infrastructure Systems }\end{array}$ & $\begin{array}{c}\text { Indiana, } \\
\text { Minnesota, Flórida, } \\
\text { Virgínia, Texas e } \\
\text { Alasca }\end{array}$ & Rodovias \\
\hline $\begin{array}{l}\text { Haroun, Elfaki e } \\
\text { Beshir (2012) }\end{array}$ & $\begin{array}{l}\text { Feasibility of adopting in-and- } \\
\text { out-sourcing. }\end{array}$ & $\begin{array}{l}\text { Journal Of Quality in } \\
\text { Maintenance } \\
\text { Engineering }\end{array}$ & Sudão & $\begin{array}{l}\text { Frota de } \\
\text { veículos } \\
\text { (caminhões) }\end{array}$ \\
\hline Rahman (2014) & $\begin{array}{l}\text { Maintenance contract model } \\
\text { for complex asset/equipment }\end{array}$ & $\begin{array}{c}\text { International Journal of } \\
\text { Reliability, Quality } \\
\text { And Safety } \\
\text { Engineering }\end{array}$ & Austrália & $\begin{array}{l}\text { Trilhos de uma } \\
\text { via férrea }\end{array}$ \\
\hline $\begin{array}{l}\text { Hassanain et } \\
\text { al. }(2015)\end{array}$ & $\begin{array}{l}\text { A multi-criteria decision- } \\
\text { making model for outsourcing } \\
\text { maintenance services }\end{array}$ & Facilities & Arábia Saudita & $\begin{array}{l}\text { Universidades } \\
\text { Públicas }\end{array}$ \\
\hline Motta et al. (2017) & $\begin{array}{l}\text { Análise de custos na } \\
\text { terceirização de serviços de } \\
\text { manutenção industrial }\end{array}$ & $\begin{array}{l}\text { XXXVII Encontro } \\
\text { Nacional de } \\
\text { Engenharia de } \\
\text { Produção (ENEGEP) }\end{array}$ & Ribeirão Preto (SP) & $\begin{array}{l}\text { Usina de açúcar } \\
\text { (caldeiras) }\end{array}$ \\
\hline
\end{tabular}



econômicos: revisão bibliográfica. Brazilian Journal of Production Engineering, 7(2), 155-168.

Anastasopoulos et al. (2010) apresentaram em seus estudos uma metodologia para estimar a probabilidade e a quantidade de economia de custos associada à aplicação de contratos baseados no tempo (Performance-based contracts - PBC) para operar a manutenção de rodovias. Para isso, compararam a manutenção interna com os métodos de contratação no que se refere aos custos, desenvolvendo modelos diferentes de acordo com o contexto aplicado. Foram utilizados os modelos logit misto, tobit, probit binário e modelos de regressão linear.

A partir da aplicação dos modelos foram alcançados resultados distintos, indicando em qual área a terceirização da manutenção é interessante em relação aos custos. Por exemplo, projetos terceirizados com contratos de longa duração (mais de 2 anos) tendem a obter melhor desempenho e, consequentemente, economia de custos especialmente no PBC. Já nas atividades específicas, como as atividades de manutenção de ponte-túnel, paisagem e acostamento não funcionaram devidamente quando terceirizadas, por isso não são incentivadas. Os resultados do estudo foram, portanto, significativos e provaram a necessidade de análise detalhada antes de tomar decisões, sendo que o modelo desenvolvido pode auxiliar nesse processo (Anastasopoulos et al., 2010).

Domberger, Jensen e Stonecash (2002), por meio de um estudo de caso sobre a terceirização dos serviços de manutenção e armazenamento de veículos em uma base do Exército da Nova Zelândia, buscaram avaliar os custos totais antes e depois da terceirização. Para apontar se a terceirização proporcionou economia de custos global, calcularam o valor presente dos custos e despesas no decorrer de toda a vida do contrato. A utilização da estrutura de valor presente possibilita contabilizar as alterações no volume de trabalho realizado de ano para ano e englobar importantes custos de transações e de transição na análise, permitindo a comparação entre os custos totais de prestação de serviços antes e depois da terceirização.

Os resultados da análise de custos indicaram que, em diferentes cenários, é possível observar economias de custo significativas com a terceirização. Alguns fatores apontados como contribuintes para a economia foram: o preço fixo da oficina teve um aumento superior ao aumento do volume de trabalho; reduções na folga de capital e de trabalho, sugerindo que aconteceu uma redução na ineficiência; o crescimento técnico que economizava mão de obra; grandes reduções no número de funcionários. Por fim, realizando a decomposição das fontes de economia, aponta que a economia veio, em maior parte, da dispensa de mão de obra (58\%), de mudanças técnicas (23\%) e da redução de salários (19\%) (Domberger et al., 2002).

Rahman (2014) desenvolveu um modelo conceitual para estimar o custo de terceirização da manutenção de ativos/equipamentos complexos e críticos, considerando as estratégias de serviço (corretiva e preventiva) e os riscos e custos de penalidades relacionados ao contrato. Essa estimativa de custos é importante e complexa para os proprietários bem como para os prestadores de serviços em relação à viabilidade econômica, pois auxilia os proprietários no momento de tomada de decisão (comparação de custos) e os prestadores para evitar perdas. Os custos considerados são dependentes da confiabilidade do ativo e das estratégias de manutenção. Propõe a utilização de softwares matemáticos como o Matlab.

O modelo de custo conceitual desenvolvido considerou uma política de contrato de manutenção simples, assumindo que o contrato encerra quando atinge um tempo ou nível de 

econômicos: revisão bibliográfica. Brazilian Journal of Production Engineering, 7(2), 155-168.

uso pré-determinado. Além disso, o contrato engloba ações de manutenção preventiva com intervalo constante a fim de prolongar a confiabilidade do sistema, bem como provisão para retificação de manutenção corretiva em caso de falha. Para simplificar o modelo, realizou cálculos para estimar o custo da manutenção, custo de inspeção, custo do risco e, somando todos estes, obtém o custo total do contrato de manutenção. Também foi considerado o custo de penalidade esperado e a possibilidade de prêmio para os prestadores de serviço (custo total de manutenção dividido pelo período do contrato). Para a demonstração do modelo, o autor utilizou dados reais referentes a manutenção de trilhos de uma via férrea. Com isso, provou-se que o modelo desenvolvido pode ser aplicável à terceirização de serviços de manutenção para quaisquer sistemas complexos reparáveis (Rahman, 2014).

Por meio de pesquisa bibliográfica, Hassanain, Assaf, Al-Hammad e Al-Nehmi (2015) identificaram trinta e oito fatores de decisão de terceirização, os quais foram classificados, de acordo com semelhanças, em seis categorias principais. A partir desses fatores, os autores desenvolveram um modelo de tomada de decisão multicritério, tendo como base o Processo de Hierarquia Analítica (Analytic Hierarchy Process - AHP) para elaborar uma estrutura de tomada de decisão para a terceirização de serviços de manutenção de universidades públicas da Arábia Saudita. Ao atribuir pesos para cada fator, o resultado obtido por esse método, geralmente, apoia a decisão de terceirizar as atividades de manutenção com prioridade de $77 \%$, porém, através do estudo de caso realizado, a decisão recomendada é para não terceirizar a manutenção dos sistemas de ar-condicionado. Apesar do fator específico "economizar o custo geral" estar entre os fatores mais importantes, o grupo de fatores "qualidade" recebeu maior importância, seguido dos fatores "econômicos" e demais. A abordagem apresentada pelo estudo pode ser utilizada por gerentes de manutenção na tomada de decisão relacionada à manutenção predial.

Haroun, Elfaki e Beshir (2012) realizaram um estudo a partir do problema de tomada de decisão da empresa PetroCost sobre manter a frota própria de veículos ou alugar (terceirizar) a mesma, consequentemente, a atividade de manutenção faz parte do processo. A empresa possuía uma frota com 229 caminhões, porém mais de $68 \%$ se encontravam fora de serviço. Os pesquisadores buscaram desenvolver uma abordagem para encontrar o efeito do valor econômico dos custos de manutenção na decisão de cada alternativa (terceirizar ou manter interno). Os autores realizaram dois estudos de caso, um do projeto em andamento existente (interno) e outro do projeto de licitação proposto (terceirizado), considerando fatores que têm efeito direto nos custos de propriedade e operação dos ativos, como: período de propriedade; preço dos consumíveis; custo de reparo e manutenção; custo de frete, frete e seguro; taxa de juro; e outros, por exemplo, custo de emergência (contingência).

Para o primeiro caso, os cálculos abrangerem, inclusive, um financiamento em banco e sua taxa de juros para reabilitar os caminhões parados e realizar a manutenção interna. A partir dos resultados obtidos, os autores demonstraram que a melhor alternativa é a reabilitação e manutenção interna. Para o segundo caso a licitação foi realizada considerando duas opções, sendo o uso do equipamento da empresa com seus custos de propriedade e operação associados, ou o aluguel, utilizando para a comparação econômica os conceitos de custo fixo e variável, custo total e receita total. Com isso, a conclusão obtida foi de que utilizando frota 

econômicos: revisão bibliográfica. Brazilian Journal of Production Engineering, 7(2), 155-168.

própria e realizando a manutenção internamente, a empresa apresenta uma economia de $33,4 \%$ em relação a alternativa de terceirização, ao passo que o projeto recupera (retorno) suas despesas em 27 dias (um terço da vida do projeto). Dessa forma, mesmo considerando três cenários diferentes, a proposta de terceirização foi considerada a menos viável economicamente (Haroun et al., 2012).

Lindemann (2006) apresentou um modelo capaz de auxiliar a decisão acerca da terceirização ou não da atividade de manutenção de embarcações, baseado na análise multicriterial, particularmente, a Teoria da Utilidade Multiatributo (MAUT). Para a aplicação, o autor apresenta uma sequência de passos que devem ser seguidos, conforme Figura 3.

Figura 3. Passos para a elaboração do modelo para auxílio à decisão.

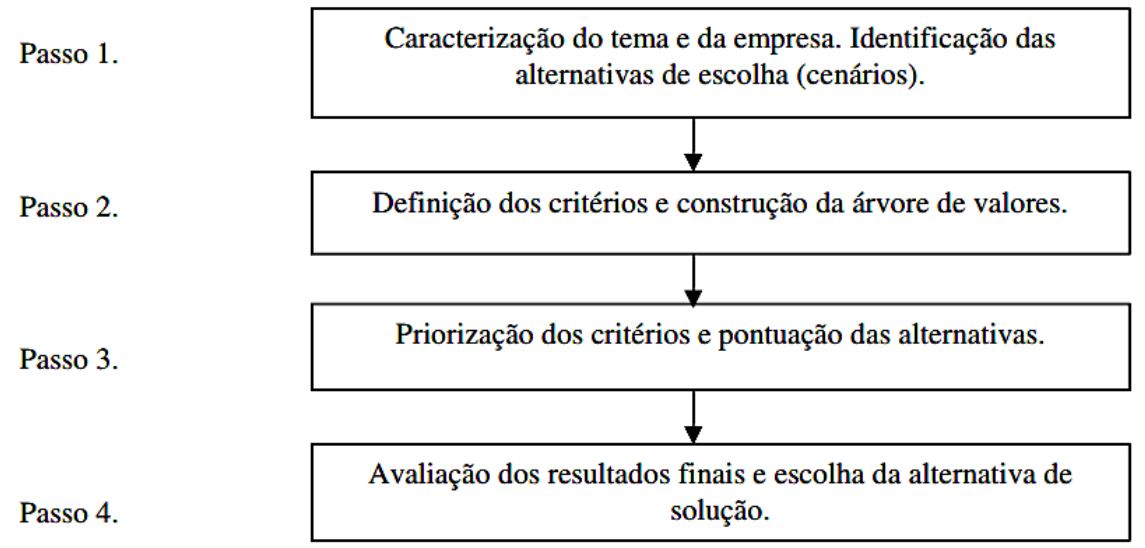

Fonte: (Lindemann, 2006)

Foram propostos pelo autor quatro cenários, sendo: por hierarquia (atual), manutenção realizada com recursos próprios; hierarquia e prestação de serviços para terceiros (foi descartado por não alinhar com os objetivos da empresa); híbrido, manutenção em estaleiro próprio em parceria com fornecedor que disponibilizaria recursos e mão-de-obra; e, por fim, mercado, totalmente terceirizado, estrutura e recursos. Foram elencados critérios e atribuídos notas e pesos aos mesmos, para definir os mais importantes e o cenário ideal. Apesar dos custos serem apontados como um dos fatores de impacto principais, pois é uma atividade dispendiosa que reflete no custo total do processo, os critérios que mais pesaram na tomada de decisão foram a qualidade e garantia de realização dos serviços de manutenção. Dessa forma, através do modelo apresentado, o cenário mais alinhado com os objetivos da empresa é o de hierarquia, adotado atualmente, pois de acordo com a visão dos administradores, proporciona maior disponibilidade das embarcações (Lindemann, 2006).

Motta et. al. (2017) realizaram um estudo de caso a fim de analisar os custos do serviço de manutenção de forma terceirizada em uma usina de açúcar e álcool durante a entressafra. Para isso, foram analisados os custos estimados de manutenção em três equipamentos na área das caldeiras, posteriormente, avaliada a possibilidade de terceirizar essa atividade. Para calcular os custos internos, se basearam em dados históricos, considerando todos os custos por trabalhador, como os salários e devidos encargos trabalhistas, incluindo EPI's, transporte diário e refeição. Já para a proposta de terceirização, analisaram os valores ofertados por quatro empresas para a contratação da mão de obra, escolhendo as opções mais próximas 
Citação (APA): Mamede, A. L. F., \& Resende, A. A. de. (2021). Análise da terceirização da manutenção sob a ótica dos custos e impactos econômicos: revisão bibliográfica. Brazilian Journal of Production Engineering, 7(2), 155-168.

(baratas) para comparação. O cálculo dos custos também inclui o valor de aluguel de guindaste, de materiais consumíveis e verba de contingência.

Com isso, após realizar todas as análises, os autores comprovaram que a manutenção, neste caso, deveria realizada com a equipe interna própria, pois foi a mais viável economicamente, representando 59,8\% a menos do que os custos estimados de terceirização. Porém, a empresa considera outros aspectos como o compartilhamento de riscos entre a contratada e contratante, por a atividade nesse setor ser muito complexa, por isso optam pela terceirização da manutenção, apesar de ser consideravelmente mais dispendiosa (Motta et al., 2017).

\section{DISCUSSÕES}

A revisão realizada durante a pesquisa evidenciou o fato de a terceirização dos serviços de manutenção não ser sempre vantajosa economicamente, principalmente pelo fato dos estudos serem em áreas distintas, logo possuem diferentes necessidades e especificidades. Com isso, também evidenciou a necessidade de analisar detalhadamente a proposta de acordo com a realidade da empresa ou setor, conforme ilustrado na Tabela 2.

Tabela 2. Opções consideradas mais viáveis (proposta) x adotadas

\begin{tabular}{|c|c|c|c|}
\hline Trabalho & Opção proposta & $\begin{array}{c}\text { Opção adotada pela } \\
\text { empresa }\end{array}$ & Fator decisivo \\
\hline $\begin{array}{c}\text { Domberger, Jensen e } \\
\text { Stonecash (2002) }\end{array}$ & Terceirização & Terceirização & Economia de custos \\
\hline Lindemann (2006) & Manutenção interna & Manutenção interna & $\begin{array}{l}\text { Qualidade e garantia } \\
\text { de realização }\end{array}$ \\
\hline $\begin{array}{c}\text { Anastasopoulos et } \\
\text { al. (2010) }\end{array}$ & $\begin{array}{c}\text { Terceirização vantajosa para } \\
\text { algumas atividades e outras } \\
\text { não }\end{array}$ & Não se aplica & Não se aplica \\
\hline $\begin{array}{c}\text { Haroun, Elfaki e Beshir } \\
(2012)\end{array}$ & Manutenção interna & Manutenção interna & Economia de custos \\
\hline Rahman (2014) & Terceirização & Não se aplica & Não se aplica \\
\hline Hassanain et al. (2015) & Manutenção interna & Manutenção interna & Qualidade \\
\hline Motta et al. (2017) & Manutenção interna & Terceirização & $\begin{array}{l}\text { Compartilhamento de } \\
\text { riscos }\end{array}$ \\
\hline
\end{tabular}

Todos os estudos encontrados apresentaram propostas e modelos para auxiliar a tomada de decisão e, ao final, apontaram a decisão mais viável de acordo com a empresa analisada. A terceirização foi considerada mais viável em três trabalhos, sendo que no de Domberger, Jensen e Stonecash (2002) avaliaram diferentes cenários e apontaram para essa decisão que foi acatada pela empresa devido a economia de custos apresentada. No estudo de Haroun, Elfaki e Beshir (2012) o fator decisivo também foi a economia de custos. Por sua vez, Anastasopoulos et al. (2010) apontaram que a terceirização é vantajosa em algumas atividades e outras não, o que varia de acordo com o tipo de contratação e do serviço. O trabalho de Rahman (2014) não fez comparação com outra forma, por isso não destacou a opção da empresa e fator decisivo.

Já nos estudos de Lindemann (2006) e Hassanain et al.(2015) a manutenção interna foi apontada e adotada como mais vantajosa devido aos fatores qualidade e garantia de realização, o que reforça os dados apresentados pelo Documento da CNI (2017) que indicam que o ganho de tempo e aumento da qualidade do serviço são os fatores mais relevantes depois da redução de custos. O trabalho de Motta et al. (2017) divergiu dos demais pois os 

econômicos: revisão bibliográfica. Brazilian Journal of Production Engineering, 7(2), 155-168.

resultados provaram que a manutenção interna era a ideal, porém a empresa optou pela terceirização pois considera primordial o compartilhamento de riscos, evidenciando que todos os aspectos precisam ser considerados no momento da decisão.

Um destaque pode ser dado aos resultados dos trabalhos de Anastasopoulos et al. (2010) e Motta et al. (2017). O primeiro demonstra que, mesmo dentro de uma mesma organização, a avaliação deve ser minuciosa e estar respaldada financeiramente, levando em conta os tipos de contratação, histórico da atividade, nível de qualificação necessária, entre outros fatores. $\mathrm{O}$ segundo ratifica o que foi apresentado no referencial teórico por Filho (2010) em relação a considerar os custos de acidentes e possíveis indenizações, devido à complexidade da atividade e risco de acidentes a empresa opta por terceirizar. Os autores Motta et al. (2017) citam inclusive um histórico de ações judiciais alto que pode ser utilizado em pesquisas futuras para incluir os custos jurídicos e reavaliar a viabilidade econômica.

Os autores incluídos no estudo desenvolveram diferentes modelos e metodologias para apoiar a tomada de decisão, alguns desenvolveram problemas matemáticos, outros autores realizaram análises multicritérios, atribuindo notas e pesos para cada critério. Outro fator destaque nos trabalhos é o tipo de contrato estabelecido a fim de englobar pontos importantes para garantir que contratante e contratado atingirão seus objetivos.

\section{CONSIDERAÇÕES FINAIS}

Através da pesquisa bibliográfica realizada neste estudo, evidenciou-se a necessidade de analisar detalhadamente todos os cenários antes de optar pela manutenção interna ou terceirizada, pois, em uma mesma empresa, pode ser viável terceirizar uma parte das atividades e outras não, sendo que nem sempre o custo será predominante na decisão, outros aspectos como qualidade e segurança, podem ser mais importantes e decisivos.

Apesar do foco do presente estudo ser a análise sob a ótica econômica, percebeu-se que o fator qualidade e garantia do serviço possui um peso grande para os contratantes, principalmente em setores que necessitam de qualificações específicas. Por fim, é importante ressaltar que existe uma lacuna muito grande de estudos aplicados nessa área, sendo uma oportunidade para desenvolvimento de trabalhos futuros.

A produção científica encontrada sobre o tema foi consideravelmente baixa, sendo que boa parte dos estudos se dedicam a avaliar modelos de contratação e gestão das parcerias entre contratante e contratado. Um possível motivo para isso pode ser explicado pelo pressuposto de que a terceirização representa uma redução dos custos gerais, logo esse fator não é tão explorado individualmente. Recomenda-se para trabalhos futuros a realização de uma análise de custos da terceirização da manutenção em diversas empresas do mesmo ramo, a fim de obter um resultado mais amplo sobre os seus impactos.

Com isso, os objetivos do trabalho foram atingidos, uma vez que foram encontrados documentos relevantes que apresentaram modelos viáveis para auxiliar a tomada de decisão, contribuindo tanto para a ciência, pois é possível realizar novas aplicações baseado nesses modelos, quanto para a prática de gestão ao permitir a aplicação na prática de modelos já validados.

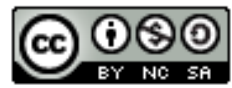



econômicos: revisão bibliográfica. Brazilian Journal of Production Engineering, 7(2), 155-168.

O principal ponto que justifica a dificuldade em tomar a decisão sobre a terceirização ou não de uma atividade de manutenção está relacionado ao fato de ser uma "atividade-meio". Assim, qualquer variação de custo e/ou qualidade no serviço de manutenção, tem impacto direto na atividade fim da empresa. Dessa forma, uma análise adequada sobre a terceirização (ou não) de serviços de manutenção, constitui de uma importante ferramenta, que se adequadamente aplicada, tem potencial para melhorar os resultados da organização.

\section{Agradecimentos}

Os autores agradecem a CAPES pela bolsa de mestrado concedida à primeira autora. Os autores também agradecem aos valiosos comentários dos revisores que contribuíram para a melhoria na qualidade do trabalho.

\section{REFERENCIAS}

ABRAMAN. Documento Nacional (2013). Situação da Manutenção no Brasil. Recuperado de http://www.abraman.org.br/arquivos/403/403.pdf

Anastasopoulos, P. C., McCullouch, B. G., Gkritza, K., Mannering, F. L., \& Sinha, K. C. (2010) Cost Savings Analysis of Performance-Based Contracts for Highway Maintenance Operations. Journal Of Infrastructure Systems, [S.L.], v. 16, n. 4, p. 251-263, dez. 2010. American Society of Civil Engineers (ASCE). http://dx.doi.org/10.1061/(asce)is.1943555x.0000012

Azevedo, P. L. (2015). Custos de Transação e Desempenho Contratual: o Caso da Terceirização da Atividade de Manutenção em Refinarias da Petróleo Brasileiro S.A. . 96 f. Dissertação (Mestrado) - Curso de Programa de Pós-Graduação em Administração, Universidade Federal de Pernambuco, Recife, 2015. Recuperado de https://attena.ufpe.br/handle/123456789/16504

BRASIL, Lei n. 6.019 (1974). Dispõe sobre o Trabalho Temporário nas Empresas Urbanas, e dá outras Providências. Recuperado de: http://www.planalto.gov.br/ccivil_03/leis/16019.htm.

BRASIL, Lei n. 13.429 (2017). Altera dispositivos da Lei n. 6.019 (1974) e dispõe sobre as Relações de Trabalho na Empresa de Prestação de Serviços a Terceiros. Recuperado de http://www.planalto.gov.br/ccivil_03/_Ato2015-2018/2017/Lei/L13429.htm

Confederação Nacional da Indústria. Sondagem Especial 68: Terceirização. Ano 18, Número 1. (2017). Recuperado de: http://www.portaldaindustria.com.br/estatisticas/sondesp-68terceirizacao/

Cruz, A. M., \& Rincon, A. M. R. (2012). Medical device maintenance outsourcing: have operation management research and management theories forgotten the medical engineering community? a mapping review. European Journal of Operational Research, [S.L.], 221(1), 186-197. http://dx.doi.org/10.1016/j.ejor.2012.02.043

Domberger, S., Jensen, P. H. \& Stonecash, R. E. (2002). Examining The Magnitude And Sources Of Cost Savings Associated With Outsourcing. Public Performance \& Management Review, [S.L.], 26(2) 148-168. http://dx.doi.org/10.1177/1530957602238260

Filho, G. B. (2010). Custos em Manutenção. Rio de Janeiro: Editora Ciência Moderna Ltda. $142 \mathrm{p}$.

Frez, G. M., \& Mello, V. M. (2017). Terceirização no Brasil. South American Development Society Journal, [S.1.], 2(4), 78-101. ISSN 2446-5763. Recuperado de http://www.sadsj.org/index.php/revista/article/view/32 

econômicos: revisão bibliográfica. Brazilian Journal of Production Engineering, 7(2), 155-168.

Galvão, T. F., Pansani, T. A., \& Harrad, D. (2015). Principais itens para relatar Revisões sistemáticas e Meta-análises: A recomendação PRISMA. Epidemiologia e Serviços de Saúde, 24(2) 335-342. Recuperado de https://www.scielo.br/j/ress/a/TL99XM6YPx3Z4rxn5WmCNCF/?lang=pt

Galvão, T. F., \& Pereira, M. G. (2014). Revisões sistemáticas da literatura: passos para sua elaboração. Epidemiologia e Serviços de Saúde, v. 23, n. 01, p. 183-184. Recuperado de http://scielo.iec.gov.br/scielo.php?script=sci_arttext\&pid=S1679-

$49742014000100018 \& \operatorname{lng}=p t \& t \operatorname{lng}=p t$

Haroun, A. E., Elfaki, E. A., \& Beshir, El Mahdi A. M. (2012). Feasibility of adopting in-andout-sourcing. Journal of Quality In Maintenance Engineering, [S.L.], 18(1), 4-15. http://dx.doi.org/10.1108/13552511211226157

Hassanain, M., Assaf, S., Al-Hammad, A., \& Al-Nehmi, A. (2015). A multi-criteria decision making model for outsourcing maintenance services. Facilities, [S.L.], 33(3/4), 229-244. http://dx.doi.org/10.1108/f-01-2013-0003

Kardec, A., \& Nascif, J. (2019). Manutenção: função estratégica. 5. ed. Rio de Janeiro: Qualitymark. 560 p. Revisada e Ampliada.

Kardec, A., \& Nascif, J. (2013) Terceirização da Manutenção: como otimizar os resultados. 1. ed. Rio de Janeiro: Qualitymark. 102 p.

Leal, A., et al. (2015). Terceirização versus primarização: um estudo na área de manutenção industrial. $\operatorname{Pr}$ Coop. Tecn. Cient., Curitiba, v.10, n.122, p.43-56, jan.2015. Recuperado de http://www.paranacooperativo.coop.br/ppc/images/Comunicacao/2016/revista_tecnico_cientif ico/10_tecnico_cientifico.pdf\#page $=45$

Lindemann, J. (2006). Modelo de Apoio à Decisão Estratégica de Terceirização da Atividade de Manutenção de Embarcações: Um Estudo de Caso. 105 f. Dissertação (Mestrado) - Curso de Faculdade de Administração, Contabilidade e Economia, Pontifícia Universidade Católica do Rio Grande do Sul, Porto Alegre.

Malhotra, N. (2001) Pesquisa de marketing. $3^{\mathrm{a}}$ ed. Porto Alegre: Bookman.

Motta, A. L. G., Motta G. A. Utiyama M. H. R., Iannoni, J. R., \& Junior, H. M. (2017). Análise de custos na terceirização de serviços de manutenção industrial. In: XXXVII Encontro Nacional de Engenharia de Produção (ENEGEP), Franca. Anais [...]. Joinville: ABEPRO,. p. 1-19. Recuperado de http://www.abepro.org.br/biblioteca/TN_STP_240_390_34775.pdf

Murthy, D. N. P., Karim, M. R., \& Ahmadi, A. (2015). Data management in maintenance outsourcing. Reliability Engineering \& System Safety, [S.L.], 142, 100-110. http://dx.doi.org/10.1016/j.ress.2015.05.002

Rahman, A. (2014). Maintenance contract model for complex asset/equipment. International Journal Of Reliability, Quality And Safety Engineering, [S.L.], 21(01), 1-11. http://dx.doi.org/10.1142/s0218539314500028

Tarakci, H., Tang, K., \& Teyarachakul, S. (2009). Learning effects on maintenance outsourcing. European Journal Of Operational Research, [S.L.], 192(1), 138-150. http://dx.doi.org/10.1016/j.ejor.2007.09.016

Tavares, L. A., Gonzaga, M. A. C., \& Poydo, P. R. S. (2005). Manutenção Centrada no Negócio. Rio de Janeiro: Novo Polo Publicações.

Xenos, H. G. P. (2014). Gerenciando a manutenção produtiva. 2. ed. Nova Lima: FALCONI Editora. 312 p. 